\title{
Interactive comment on "Rainfall drives atmospheric ice nucleating particles in the maritime climate of Southern Norway" by Franz Conen et al.
}

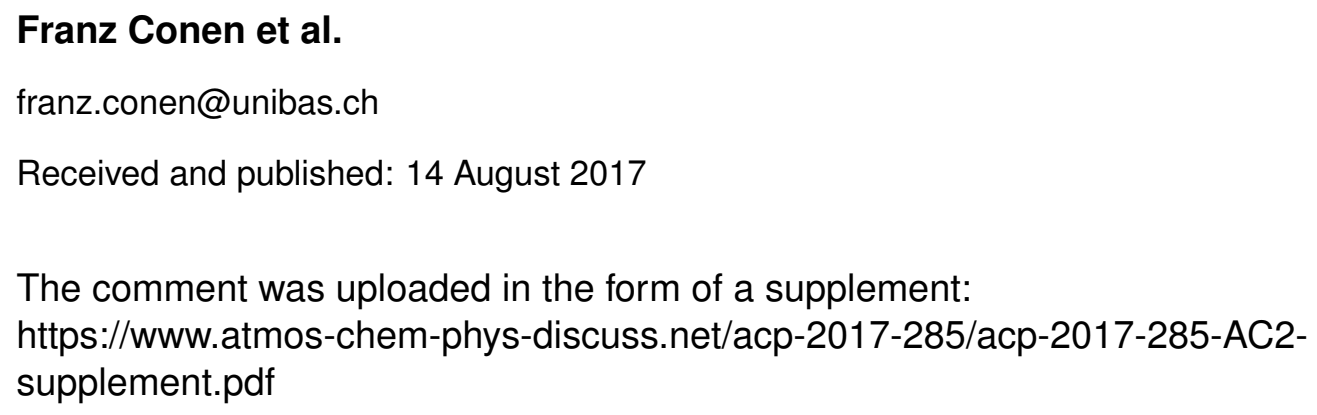

The comment was uploaded in the form of a supplement: https://www.atmos-chem-phys-discuss.net/acp-2017-285/acp-2017-285-AC2supplement.pdf 2017. 